\title{
A case of multiple evanescent white dot syndrome misdiagnosed as optic neuritis: Differential diagnosis for the neurologist
}

\author{
Francesco Pellegrini, Emanuela Interlandi \\ Department of Ophthalmology, Conegliano Hospital, Conegliano, Treviso, Italy
}

\section{ABSTRACT}

A 25-year-old female presented to a local hospital for acute onset of a central scotoma in the left visual field. She was visited by the neurologist, and a diagnosis of left retrobulbar optic neuritis was made. Magnetic resonance imaging scan was normal. Ophthalmic examination revealed a multiple evanescent white dot syndrome. After a description of the case, a brief differential diagnosis between these two entities is made. The neurologist should be aware of this uncommon condition.

Key words: Multiple evanescent white dot syndrome, optic neuritis, visual loss

\section{Introduction}

Even nowadays, it happens too often that an optic neuritis is misdiagnosed for something else. This is due in part to the misconception that a young woman with acute visual loss in one eye has most probably a disease of the optic nerve; difficulty in pupil examination, incomplete collection of key points in past history, and lack of knowledge of other entities are other factors. Here, we present a case of multiple evanescent white dot syndrome (MEWDS) misdiagnosed as optic neuritis.

\section{Case Report}

A 25-year-old female presented to a local hospital for acute onset of a central scotoma in the left visual field. The neurologist collected a visual acuity (VA) of 20/20 in OD and 10/20 in OS; pupil examination as well as

\section{Address for correspondence:}

Dr. Francesco Pellegrini, Via D. Manin 110,

Conegliano, Treviso, Italy.

E-mail: francepellegrini@virgilio.it

\begin{tabular}{|l|l|}
\hline \multicolumn{2}{|c|}{ Access this article online } \\
\hline Quick Response Code: & Website: \\
\hline & www.ruralneuropractice.com \\
\cline { 2 - 2 } & \\
\hline & \\
\hline
\end{tabular}

optic nerve examination by direct ophthalmoscopy was normal. A retrobulbar optic neuritis was suspected so that a contrast brain magnetic resonance imaging scan was requested. This resulted normal with no signs of optic neuritis or multiple sclerosis. She was sent to neuro-ophthalmology, where she presented 2 weeks later. Her past ocular history was positive for mild myopia (-1.75 SF OU); she denied smoke, trauma, or drug consumption, but to specific questioning, the patient reported a flu-like illness 1 month before the onset of her symptoms. She denied pain on eye movement when presented the $1^{\text {st }}$ time with visual loss. The neurologic examination was normal. Her VA was $20 / 20$ in OD and $15 / 20$ in OS. Pupils were equal a briskly reactive to light with no relative afferent pupillary defect (RAPD). Ishihara test was full OD (12/12) but abnormal in OS (7/12); anterior segment examination and intraocular pressure were within normal limits in OU. On fundus examination, a granular appearance of the macula [Figure 1] was evident in OS with some residual white spots in the posterior pole [Figure 2]. Fundus examination in OD was normal. Optical coherence tomography scan of the

This is an open access article distributed under the terms of the Creative Commons Attribution-NonCommercial-ShareAlike 3.0 License, which allows others to remix, tweak, and build upon the work non-commercially, as long as the author is credited and the new creations are licensed under the identical terms.

For reprints contact: reprints@medknow.com

How to cite this article: Pellegrini F, Interlandi E. A case of multiple evanescent white dot syndrome misdiagnosed as optic neuritis: Differential diagnosis for the neurologist. J Neurosci Rural Pract $2016 ; 7: 283-5$. 
macula was positive for a disruption of outer retinal layers [Figure 3] well matching the granular appearance of retinography. Autofluorescence [Figure 4] revealed a major number of white spots as compared to fundus examination. The patient refused the consent for visual field and indocyanine green angiography. She was diagnosed with MEWDS and scheduled for control at 3 months.

\section{Discussion}

MEWDS is an uncommon entity first described in 1984 by Jampol et al. as a unilateral VA loss notable for white dots of the "the retinal pigment epithelium (RPE) or deep retina and a granularity of the fovea."[1] An infectious etiology is thought to be involved in the pathogenesis of MEWDS since frequently, but not always, there is a viral prodrome. The white dot syndromes produce yellow-white retinal lesions located at the RPE or outer retina level and are found primarily in young patients. Within this diagnostic group are MEWDS, acute posterior multifocal placoid pigment

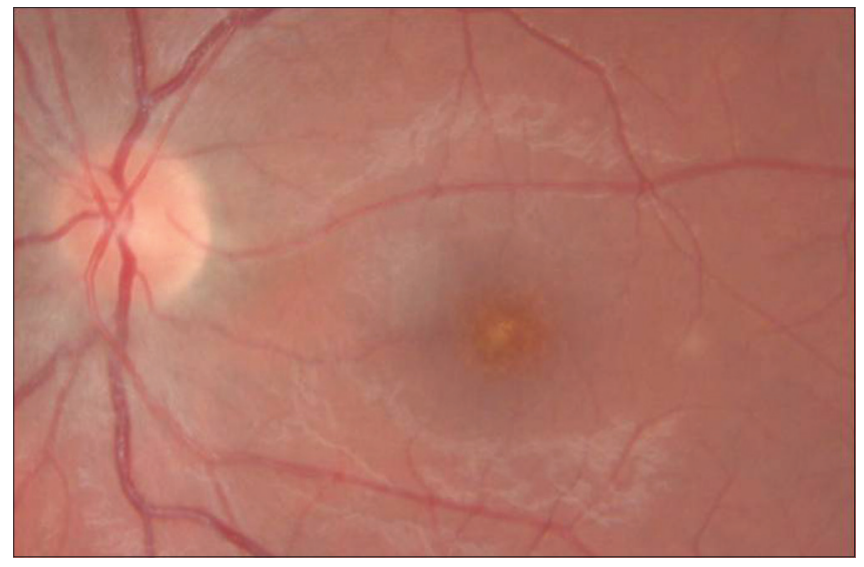

Figure 1: Granular appearance of the macula is pathognomonic of the condition

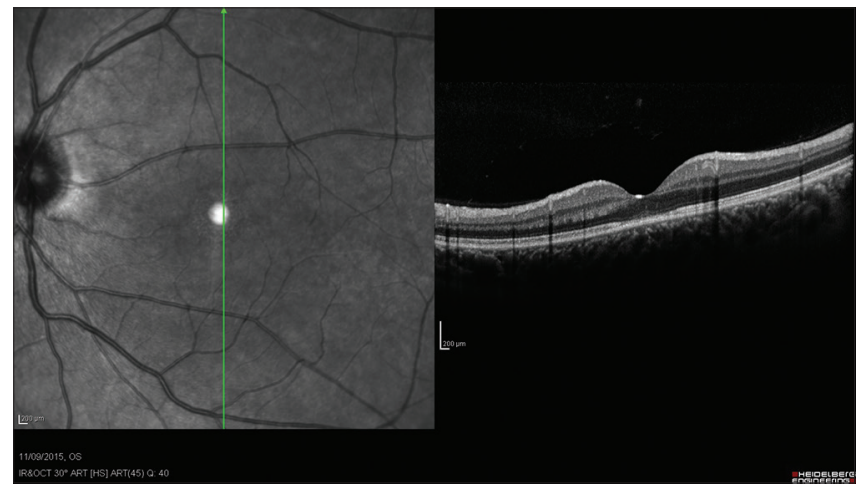

Figure 3: Optical coherence tomography scan of the fovea outer segment shows disruption at the inner segment/outer segment junction of photoreceptor layer in the macula epitheliopathy, multifocal choroiditis and panuveitis, punctate inner choroiditis, birdshot retinopathy, acute zonal occult outer retinopathy, and serpiginous choroidopathy. ${ }^{[2]}$ Since MEWDS is unilateral, causes visual loss, and occurs predominantly in young women, it may be confused with optic neuritis. Key points in the differential diagnosis are:

- Lack of eye pain exacerbated by eye movements in MEWDS as compared to optic neuritis

- Predominant color vision and contrast loss as compared to VA in optic neuritis

- An RAPD is evident in optic neuritis (some trace can be seen in MEWDS but uncommon)

- Chief complaints of patients: Blurred vision and color vision impairment in optic neuritis, delineated central/paracentral scotoma in MEWDS

- The characteristic features of MEWDS are multiple retinal white dots and foveal granularity on fundus examination.

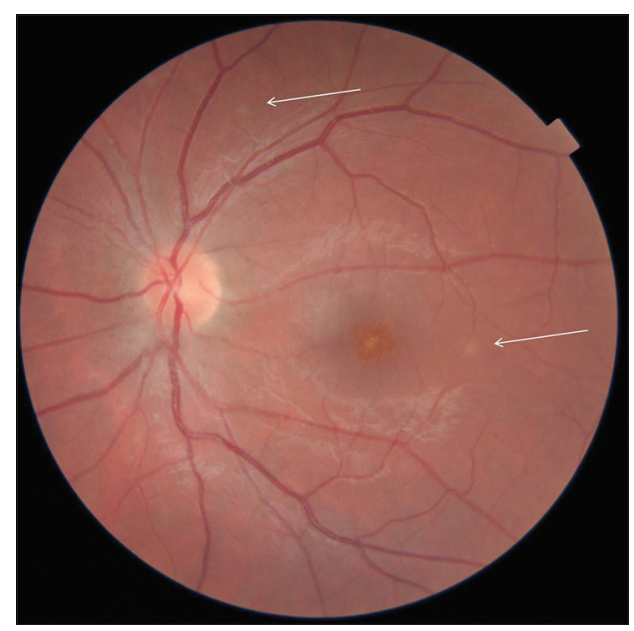

Figure 2: Retinography of the left eye. Arrows indicate residual white dots

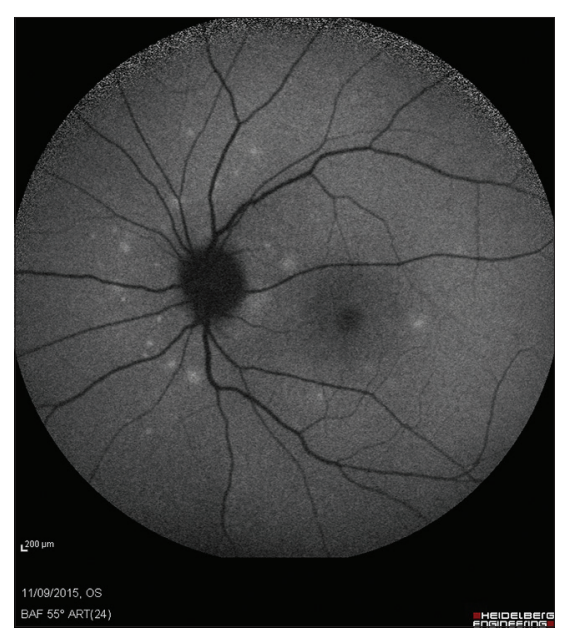

Figure 4: Posterior pole autofluorescence outer segment shows multiple white dots concentrated in the peripapillary area 
The condition is usually self-limiting, with excellent recovery. Rarely, it recurs or is associated with complications (e.g., choroidal neovascularization). The neurologist should be aware of this condition, and in doubt, schedule the patient for a detailed ophthalmic examination after pupil dilatation. This may avoid unnecessary and expensive radiologic testing.

\section{Financial support and sponsorship}

Nil.

\section{Conflicts of interest}

There are no conflicts of interest.

\section{References}

1. Jampol LM, Sieving PA, Pugh D, Fishman GA, Gilbert H. Multiple evanescent white dot syndrome. I. Clinical findings. Arch Ophthalmol 1984;102:671-4.

2. Abu-Yaghi NE, Hartono SP, Hodge DO, Pulido JS, Bakri SJ. White dot syndromes: A 20-year study of incidence, clinical features, and outcomes. Ocul Immunol Inflamm 2011;19:426-30. 